\title{
Assessment of Nurses' Performance Regarding Care for Neonates with Necrotizing Enterocolitis at Intensive Care Units
}

\author{
Ahmed M. Zaki *;Ebtisam M. El-Sayed **; Khadiga. M. Said ***; Rehab. H. Ali ****. \\ * Pediatric Surgery - Faculty of Medicine - Ain Shams University \\ ** Pediatric Nursing - Faculty of Nursing - Tanta University \\ *** Pediatric Nursing - Faculty of Nursing - Benha University \\ ***** B.Sc. in Nursing Science
}

\begin{abstract}
Background: Necrotizing enterocolitis is an acquired condition. It is the most common gastrointestinal emergency in the neonatal period and manifested by ischemic necrosis of the intestinal mucosa. Aim of the study was to assess nurses' knowledge and performance regarding care of neonate with necrotizing enterocolitis at neonatal intensive care units. Design: A descriptive research design was utilized in this study. Settings: the study was conducted at neonatal intensive care units of Benha Specialized Pediatric Hospital. Sample: A convenient sample of 60 nurses and 50 high risk neonates had necrotizing enterocolitis were included. Tools of data collection; Two tools were used to collect data: A structured interviewing questionnaire sheet (tool 1) to collect sociodemographic data of nurses and their knowledge about necrotizing enterocolitis, an observational checklist (tool 2) was modified by the researcher to assess nurses' performance regarding care of neonate with necrotizing enter colitis. Results: The present study revealed that; more than two thirds of the studied nurses had an average level of knowledge, two thirds of them, their performance were unsatisfactory and there was a positive relation between total knowledge and performance scores of studied nurses and their personal characteristics. Conclusion: There was a positive correlation between total nurses' knowledge and their performance. Recommendations: Developing training programs regarding care of neonates with necrotizing enterocolitis for the nurses working at neonatal intensive care units is important to improve their knowledge and performance.
\end{abstract}

Key words: Nurses' performance, Necrotizing enterocolitis, Neonatal Intensive Care Unit.

\section{Introduction}

High risk neonate is defined as neonate which is susceptible to illness or death due to dysmaturity, immaturity, physical disorders, or complications at birth. From a scientific point of view, the study of newborn neurobehavior, we may provide interpretation for later behavioral outcomes. From a practical point of view, the early detection of neonates with poor developmental outcome would invite the study of preventive interventions that could reduce the severity of long term developmental deficits (Ambalavanan, 2011).

A thorough, systematic physical assessment is an essential component in the care of the high-risk neonate. Subtle changes in feeding behavior, activity, 
color, oxygen saturation, or vital signs often indicate an underlying problem. The high risk neonate, especially the extremely low birth weight (ELBW) neonate, is not able to withstand prolonged physiologic stress and may die within minutes of exhibiting abnormal symptoms if the underlying pathologic process is not corrected. The alert nurse should be aware of subtle changes and reacts promptly to implement interventions that promote optimum function in the high-risk neonate (Bucher, 2013).

Observational assessments of the high-risk neonate are made according to the neonate's acuity (seriousness of condition); they require close observation and assessment of respiratory function, including continuous pulse oximetry, electrolytes, and blood gases. Accurate documentation of the neonate's status is an integral component of nursing care. With the aid of continuous, sophisticated cardiopulmonary monitoring, nursing assessments and daily care can be coordinated to allow for minimum handling of the neonate to decrease the effects of environmental stress (Cloherty and John, 2012).

Necrotizing EnteroColitis (NEC) is an acquired condition and manifested by ischemic necrosis of the intestinal mucosa. It is the most common gastrointestinal emergency in the neonatal period. It is associated with inflammation, invasion of enteric gas forming organisms, and dissection of gas into the muscularis and portal venous system. The entire gastrointestinal (GI) tract, from the stomach to the anus, is susceptible, also, the distal small bowel and proximal colon are involved most frequently (Dominguez and Moss, 2012).

Necrotizing EnteroColitis (NEC) remains the leading cause of neonatal mortality and morbidity. It is more prevalent in lower gestational age and lower birth weight groups. Its incidence is highly variable worldwide. It accounts for 1 to 3 cases per 1000 live births, affecting almost $10 \%$ of all neonates with a birth weight under $1500 \mathrm{~g}$ and up to $5 \%$ of admission to neonatal intensive care units, with a mortality rate of $15-30 \%$ (Patel and Shah, 2012).

The pathogenesis of NEC is still incompletely understood, but it is thought that several factors are involved interactively, such as premature birth, low birth weight, ischemia/reperfusion (I/R) injury, abnormal gut bacterial colonization, and inappropriate enteral feeding. The observation of clustering of cases suggests possible infectious etiology, and yet no single one infectious agent has been consistently linked to the outbreaks of NEC. The obscure multifactorial etiology, early diagnosis and effective treatment of NEC is limited. Consequently, effective strategies in the prevention of NEC are critically needed (Cassir, et al.,2016) .

Symptoms of NEC may include vomiting, diarrhea, bloody stool, feeding intolerance, swollen abdomen, and absence of bowel sounds. It may therefore be difficult to distinguish mild cases of NEC from other gastrointestinal conditions, such as cow's milk protein intolerance. Advanced cases may show fluid in the peritoneal cavity, bowel perforation, peritonitis, or shock (Gordon and Swanson, 2014).

High risk neonate with NEC experience both short- and longterm GI morbidities. Because of the dysfunction or absence of bowel after surgical removal of necrotic intestine, neonates face clinical problems associated with short bowel syndrome including malabsorption and failure to thrive. 
Approximately $25 \%$ of high risk neonates with NEC experience some degree of short bowel syndrome. Factors that determine the severity of short bowel syndrome comprise the length of residual intestine after surgery, the anatomy of the remaining small bowel, the length of colon present, the age at resection, and the time allowed for adaptation (Clark, et al., 2011).

Effective prevention and treatment strategies are a challenge as the etiology of NEC remains uncertain. The most effective way to decrease morbidity and mortality from NEC would be to decrease the number of preterm births. Beside that, there are many evidence-based approaches to prevent NEC. These include withholding enteral feedings; using enteral antibiotics; feeding the neonate with breast milk; administering probiotic agents, or both; and administering various growth factors, anticytokine agents, and glucocorticoids (Zhou, et al., 2015).

Most NEC cases are treated medically, but severe cases may require surgical removal of the necrotic tissue. The severity of intestinal involvement influences the decision for medical or surgical management. Each course of treatment introduces particular nutritional concerns; however, some aspects of nutritional management common to both medical NEC and surgical NEC (Afrazia, et al., 2011) .

Nurse play an important role in early identification of developing NEC to reduce the devastating effects of the disease. Nurses are in a unique position to assess early signs and symptoms of NEC, when they are present. They are often the first to respond to acute changes in clinical status and physical assessments, initiating the series of events to diagnose and treat NEC. The role of nurses in performing critical assessments and their awareness of early identifiers contribute greatly to early recognition and management of long-term medical and surgical sequelae of NEC (Ball, et al.,2012).

The neonate should be made Nothing Per Mouth (NPO) once NEC is strongly suspected or confirmed. Management of fluids and electrolytes is critical in the initial phase of severe NEC, and intravenous fluids in addition to Parenteral Nutrition (PN) may be required to treat acidemia, and adjust electrolytes. PN should be initiated as soon as possible, utilizing central access if adequate enteral support will not be reached within two weeks (Leopardo,2012).

The nurse play an important role in postoperative care. She should checks physician's orders after the neonate come back from surgery. First she should look at the neonate's airway and breathing, check the skin color and temperature as well as she must check the neonate's level of consciousness, and take vital signs (Kim, 2010).

\section{Subjects and Method}

\section{1-Technical design:}

\section{A. Research design :}

A descriptive research design was used to conduct this study.

\section{B. Settings:}

The study was conducted at medical and surgical neonatal intensive care units of Benha Specialized Pediatric Hospital. The capacity of medical unit is 28 incubators and the surgical unit 12 incubators. 


\section{Sample:}

1- A convenient sample of 60 nurses working in the previously mentioned setting were included in the study (39 from medical unit +21 from surgical unit).

50 high risk neonates with necrotizing enterocolitis who were admitted during 6 months (from April to the end of September 2015) were included. neonates:

- Inclusion criteria for high risk

-Neonates with necrotizing enterocolitis of both sexes with no complications or congenital anomalies.

\section{2- Tools of data collection:}

3- Two tools were used to collect the required data.

\section{Tool (1): A Structured Interview} Questionnaire Sheet:

It was developed by the researcher after review the related literature to collect:

\section{Part (1):}

-Personal characteristics of nurses such as: age, sex, qualification, marital status, years of experience and attendance of previous educational programs about care of neonates with necrotizing enterocolitis .

- Personal characteristics of high risk neonates includes: gestational age, birth weight, sex and current weight.

\section{Part (2):}

Nurses' knowledge about necrotizing enterocolitis includes definition, clinical picture, risk factors, complications, prevention of the disease. It includes 12 close ended questions.

\section{Part (3):}

Nurses' performance regarding care provided to neonates with NEC such as pre and postoperative care, wound and nasogastric tube care. It includes 7 open ended questions and 3 close ended questions.

\section{knowledge}

Scoring system for nurses'

\begin{tabular}{|l|ll|}
\hline \multicolumn{2}{|c|}{ Scoring item } & \multicolumn{2}{c|}{ score } \\
\hline Complete\& correct & 2score & was \\
\hline Correct but incomplete & 1score & was \\
\hline Incorrect or no answer & 0score & was \\
\hline
\end{tabular}

Scoring system for level of total

knowledge: (22 questions)

\begin{tabular}{|l|l|}
\hline Level of knowledge & \multicolumn{1}{|c|}{ percent } \\
\hline Good knowledge & From 29 to $\leq 44$ \\
\hline Average knowledge & From 15 to $\leq 29$ \\
\hline Poor knowledge & From 0 to $\leq 15$ \\
\hline
\end{tabular}

Checklists :

\section{Tool (2): Observational}

It was modified by the researcher after review related literature and textbooks to assess the actual nursing performance regarding care provided to neonates with necrotizing enterocolitis. 


\section{Scoring system for each}

\begin{tabular}{|l|l|}
\hline Scoring item & \multicolumn{1}{c|}{ score } \\
\hline Completely done & 2 score was given \\
\hline Incompletely done & 1 score was given \\
\hline Not done & 0 score was given \\
\hline
\end{tabular}
performance:

Scoring system for level of total

\begin{tabular}{|l|l|}
\hline $\begin{array}{l}\text { Level of total } \\
\text { performance }\end{array}$ & \multicolumn{1}{c|}{ percent } \\
\hline Satisfactory & $80 \%-100 \%$ \\
\hline Unsatisfactory & Less than $80 \%$ \\
\hline
\end{tabular}

\section{- Administrative design:}

- Approvals to conduct the study were obtained from the authorized personnel concerned the title, objectives and tools. The study technique was illustrated to authorized personnel to gain their cooperation which was needed to allow the researcher to meet nurses at chosen setting.

\section{Ethical considerations:}

- The aim of the study was explained to all nurses before applying the tools to gain their trust and confidence. They were informed that the study is harmless.

- The researcher secured that all of the gathered data are confidential and are used only for the purpose of the study.

- The nurses were informed that they had option to participate or withdraw at any time.

\section{2-Operational design:}

- Includes preparatory phase, pilot study and field work.

\section{- Preparatory phase:}

Extensive review of the current and past available national and international references related to the research title was done (using textbooks, articles, magazines, and interne)t

\section{- Pilot study:}

-Pilot study was conducted on $10 \%$ of the total size of the sample.

Modification was done as needed and it was excluded from study sample.

\section{C- Field work:}

1. Data collection was done 3 days / week by researcher during different shifts.

2. An observational checklist ( tool 2) was used by researcher to assess nurses' performance regarding nasogastric tube, pre and postoperative care, wound care, I.V infusion and discharge care plan. It was used three times for each procedure and the average was taken.

3. A structured interview questionnaire (tool 1) was used to collect the necessary data about nurses' knowledge. Nurses were individually interviewed. The time needed for completion of questionnaire form was around 20 30 minutes.

4. The study was implemented within 6 months from the beginning of 
April 2015 to the end of September 2015.

\section{- Tool validity/ reliability:}

- Tools were submitted to a jury of seven experts in pediatric nursing to be sure for tools items clarity and content validity.

- The reliability of tools was done to determine the extent to which items were related to each other using cronbachs' alpha coefficient test.

\section{3- Statistical design:}

- Data were coded and transformed into specially designed form to be suitable for computer data entry process. Data were manipulated and analyzed using SPSS (Statistical Package for Social Science) version 20. Graphics were done by using Excel program.

-Descriptive statistics (e.g. mean and percentages), test of significance, fisher exact test and Pearson correlation coefficients were used.

\section{Results}

Table (1): Percentage distribution of the studied nurses regarding their personal characteristics $(n=60)$

\begin{tabular}{|c|c|c|}
\hline \multirow[b]{2}{*}{ Personal characteristics } & \multicolumn{2}{|c|}{$n=60$} \\
\hline & No & $\%$ \\
\hline \multicolumn{3}{|l|}{ Age ( years) } \\
\hline$<20$ & 8 & 13.3 \\
\hline $20<25$ & 17 & 28.3 \\
\hline $25<30$ & 22 & 36.7 \\
\hline$\geq 30$ & 13 & 21.7 \\
\hline Mean \pm SD & \multicolumn{2}{|c|}{$25.93 \pm 4.36$} \\
\hline \multicolumn{3}{|l|}{ Educational level } \\
\hline Diploma & 25 & 41.7 \\
\hline Technical Institute & 18 & 30.0 \\
\hline Bachelor of Nursing & 15 & 25.0 \\
\hline Postgraduate studies & 2 & 3.3 \\
\hline \multicolumn{3}{|l|}{ Experience years } \\
\hline$<3$ & 24 & 40.0 \\
\hline $3<6$ & 9 & 15.0 \\
\hline $6<9$ & 17 & 28.3 \\
\hline$\geq 9$ & 10 & 16.7 \\
\hline Mean \pm SD & \multicolumn{2}{|c|}{$4.82 \pm 3.26$} \\
\hline \multicolumn{3}{|l|}{ Attendance of previous training courses } \\
\hline yes & 47 & 78.3 \\
\hline No & 13 & 21.7 \\
\hline
\end{tabular}

Table1 shows the personal characteristics of the studied nurses. It was revealed that, $36.7 \%$ of the studied sample their aged from $25<30$ years, with the mean of $25.93 \pm 4.36$ years. Regarding to their educational level , $41.7 \%$ of them had diploma, $40.0 \%$ had less 
than 3 years of experience with the mean of $4.82 \pm 3.26$. Regarding to attendance of previous training courses, it was found that $78.3 \%$ attended training courses regarding neonatal care.

Table (2): Percentage distribution of the studied neonates regarding their sociodemographic characteristics $(n=50)$ :

\begin{tabular}{|c|c|c|}
\hline Socio-demographic Characteristics of neonates & No. & $\%$ \\
\hline $\begin{array}{l}\text { Gestational age (weeks): } \\
26-<30 \\
30-<34 \\
34-<38 \\
38-<42\end{array}$ & $\begin{array}{c}4 \\
16 \\
25 \\
5\end{array}$ & $\begin{array}{c}8.0 \\
32.0 \\
50.0 \\
10.0\end{array}$ \\
\hline \multicolumn{3}{|c|}{$\mathrm{X}+\mathrm{SD}=33.6+2.8$} \\
\hline $\begin{array}{l}\text { Gender: } \\
\text { - Male } \\
\text { - Female }\end{array}$ & $\begin{array}{l}28 \\
22\end{array}$ & $\begin{array}{l}56.0 \\
44.0\end{array}$ \\
\hline $\begin{array}{l}\text { Weight at birth }(\mathrm{gm}): \\
<1500 \\
-1500<2000 \\
-2000<2500 \\
-2500 \text { and more }\end{array}$ & $\begin{array}{c}9 \\
17 \\
21 \\
3\end{array}$ & $\begin{array}{c}18.0 \\
34.0 \\
42.0 \\
6.0\end{array}$ \\
\hline \multicolumn{3}{|c|}{$\mathrm{X}+\mathrm{SD}=1800.8+306.9$} \\
\hline $\begin{array}{l}\text { Weight at the time of study }(\mathrm{gm}): \\
<1500 \\
-1500<2000 \\
-2000<2500 \\
-2500 \text { and more }\end{array}$ & $\begin{array}{c}7 \\
16 \\
20 \\
7\end{array}$ & $\begin{array}{l}14.0 \\
32.0 \\
40.0 \\
14.0\end{array}$ \\
\hline \multicolumn{3}{|c|}{$\mathrm{X}+\mathrm{SD}=1980.8+269.7$} \\
\hline
\end{tabular}

Table 2; presents sociodemographic characteristics of the studied neonates. It was revealed that, the age of half of them $(50.0 \%)$ ranged between $34-<38$ weeks of gestation with the mean of gestational age 33.6+2.8. It was observed that male neonate constituted $56.0 \%$ of the total sample of the studied neonates. Regarding to neonate's birth weight, it was noticed that $42.0 \%$ of the studied neonates were between 2000 up to $<2500$ grams with the mean birth weight $1800.8+306.9$. While the weight of $40.0 \%$ of the studied neonates at the time of the study were between 2000 up to $<2500$ grams with the mean of weight $1980.8+269$ 
Table (3 ):-Relation between sociodemographic characteristics of studied nurses and their total level of knowledge scores $(n=60)$

\begin{tabular}{|c|c|c|c|c|c|c|}
\hline \multirow{2}{*}{\begin{tabular}{l}
\multicolumn{1}{c}{ Total nurses' } \\
knowledge score \\
Socio \\
demographic characteristics
\end{tabular}} & \multicolumn{2}{|c|}{$\begin{array}{c}\text { Good } \\
\text { knowledge } \\
\text { n=18 }\end{array}$} & \multicolumn{2}{|c|}{$\begin{array}{c}\text { Average } \\
\text { knowledge } \\
n=42\end{array}$} & \multirow[t]{2}{*}{$X^{2}$} & \multirow[t]{2}{*}{$\mathbf{P}$ - value } \\
\hline & No & $\%$ & No & $\%$ & & \\
\hline \multicolumn{7}{|l|}{ Age ( years) } \\
\hline$<20$ & 5 & 27.8 & 3 & 7.1 & FET & \\
\hline $20<25$ & 7 & 38.9 & 10 & 23.8 & 7.821 & $0.050^{*}$ \\
\hline $25<30$ & 4 & 22.2 & 18 & 42.9 & & \\
\hline$\geq 30$ & 2 & 11.1 & 11 & 26.2 & & \\
\hline \multicolumn{7}{|l|}{ Educational level } \\
\hline Diploma & 5 & 27.8 & 20 & 47.6 & FET & \\
\hline Technical Institute & 4 & 22.2 & 14 & 33.3 & 8.995 & $0.029 *$ \\
\hline Bachelor of Nursing & 9 & 50.0 & 6 & 14.3 & & \\
\hline postgraduate studies & 0 & 0.0 & 2 & 4.8 & & \\
\hline \multicolumn{7}{|l|}{ Years of experience } \\
\hline$<3$ & 13 & 72.2 & 11 & 26.2 & FET & \\
\hline $3<6$ & 3 & 16.7 & 6 & 14.3 & 14.484 & $0.002 *$ \\
\hline $6<9$ & 0 & 0.0 & 17 & 40.5 & & \\
\hline$\geq 9$ & 2 & 11.1 & 8 & 19.0 & & \\
\hline
\end{tabular}

* A statistical significant difference $(\mathrm{P} \leq 0.05) \mathrm{FET}=$ Fisher Exact Test

Table 3 reveals the relations between sociodemographic characteristics of studied nurses and their total knowledge scores. It was found that there was statistical significant relations between sociodemographic characteristics of nurses such as (age, educational level and years of experience) and their level of knowledge scores $;(\mathbf{P} \leq \mathbf{0 . 0 5})$. 
Table (4):- Relation between personal characteristics of studied nurses and their total performance scores $(n=60)$

\begin{tabular}{|c|c|c|c|c|c|c|}
\hline \multirow{2}{*}{$\begin{array}{l}\text { Total nurses' } \\
\begin{array}{l}\text { performance } \\
\text { level }\end{array} \\
\text { Socio- } \\
\text { demographic } \\
\text { characteristics }\end{array}$} & \multicolumn{2}{|c|}{$\begin{array}{c}\text { Satisfactory } \\
\mathbf{n}=20\end{array}$} & \multicolumn{2}{|c|}{$\begin{array}{c}\text { Unsatisfactory } \\
n=40\end{array}$} & \multirow[t]{2}{*}{$\mathbf{X}^{2}$} & \multirow[t]{2}{*}{$P$ - value } \\
\hline & No & $\%$ & No & $\%$ & & \\
\hline \multicolumn{7}{|l|}{ Age ( years) } \\
\hline$<20$ & 8 & 40.0 & 0 & 0.0 & FET & \\
\hline $20<25$ & 7 & 35.0 & 10 & 25.0 & 22.196 & $0.000 * *$ \\
\hline $25<30$ & 3 & 15.0 & 19 & 47.5 & & \\
\hline$\geq 30$ & 2 & 10.0 & 11 & 27.5 & & \\
\hline \multicolumn{7}{|l|}{ Educational level } \\
\hline Diploma & 7 & 35.0 & 18 & 45.0 & FET & \\
\hline Technical Institute & 3 & 15.0 & 15 & 37.5 & 11.070 & $0.011^{*}$ \\
\hline Bachelor of Nursing & 10 & 50.0 & 5 & 12.5 & & \\
\hline postgraduate studies & 0 & 0.0 & 2 & 5.0 & & \\
\hline \multicolumn{7}{|l|}{ Experience years } \\
\hline$<3$ & 15 & 75.0 & 9 & 22.5 & FET & \\
\hline $3<6$ & 2 & 10.0 & 7 & 17.5 & 16.252 & $0.001 * *$ \\
\hline $6<9$ & 1 & 5.0 & 16 & 40.0 & & \\
\hline$\geq 9$ & 2 & 10.0 & 8 & 20.0 & & \\
\hline
\end{tabular}

* A statistical significant difference $(\mathbf{P} \leq \mathbf{0 . 0 5})$ FET $=$ Fisher Exact Test

**A highly statistical significant difference $(\mathrm{P} \leq 0.001)$

Table 4 presents the relations between personal characteristics of studied nurses and their total performance scores. It was observed that there was a statistical significant relation between educational level and their performance level as well as there was highly statistical significant relations between total scores of nurses' performance and their age and years of experience.

Table(5):- Correlation between total knowledge and total performance scores of the studied nurses $(n=60)$

\begin{tabular}{|c|c|c|c|c|c|c|c|}
\hline Total & \multicolumn{2}{|c|}{$\begin{array}{c}\text { Good } \\
\mathbf{n = 1 8}\end{array}$} & \multicolumn{2}{c|}{$\begin{array}{c}\text { Average } \\
\mathbf{n = 4 2}\end{array}$} & $\mathbf{X}^{2}$ & $\begin{array}{c}\text { P }- \\
\text { value }\end{array}$ & r \\
$\begin{array}{c}\text { knowledge } \\
\text { scores of nurses }\end{array}$ & No & $\%$ & No & $\%$ & & & \\
\cline { 2 - 9 } $\begin{array}{c}\text { Total } \\
\text { performance scores of nurses }\end{array}$ & & & & & & & \\
\hline Satisfactory performance & 14 & 77.8 & 6 & 14.3 & FET & & \\
\hline Unsatisfactory performance & 4 & 22.2 & 36 & 85.7 & 22.0857 & 0.000 & 0.799 \\
\hline
\end{tabular}

* A statistical significant difference $(\mathrm{P} \leq 0.05) \quad$ FET $=$ Fisher Exact Test

**A highly statistical significant difference $(\mathrm{P} \leq 0.001)$ 
Table 5 shows correlation between total knowledge and total performance scores of the studied nurses. It was observed that there was a positive correlation between total scores of knowledge and total scores of performance.

\section{Discussion}

On the light of the study findings (table 1), the study revealed that nearly one third of the studied nurses, their age were ranged from 20 to less than 25 years and more than one third were ranged from 25 to less than 30 years. This result could be related to the younger nurses were almost working in intensive care units which considered as a dynamic and fast moving environment which needs an active young nurse. This result agreed with Fayed (2009), Faculty of Nursing, Ain Shams University, Egypt, in a study about assessment of pre and post operative care given by nurses to children with intussusception, and reported that the highest percentage of the nurses' age ranged from 20 to less than 30 years.

In relation to the educational level of studied nurses the present study proved that, nearly half of them had diploma of secondary school of nursing and exactly quarter of them had bachelor degree in nursing. This may be due to the fact that, the number of secondary school of nursing graduates are more than the number graduated from faculty of nursing. Similar findings in the study done by Ibrahim (2013), Benha University, Egypt, about "assessment of nursing care given for children with intestinal obstruction" which proved that, highest percentage of nurses had a diploma of secondary of school of nursing. Additonally, these findings were supported by the finding of Ahmed (2013), Benha University, Egypt, in a study entitled "Quality of Nursing Care to Neonates Pre-Post Operation with Tracheotomy", and reported that, more than half of nurses had nursing diploma. Loutfy (2014) in a study entitled "Quality of Nursing Care Provided for Preterm Infants Suffering from Respiratory Distress Syndrome", found that, the majority of the studied nurses had bachelor in nursing science.

As regards nurses' years of experience, the result of the present study (table1) revealed that, nearly half of studied nurses had less than 3 years of experience. This result could be related to nurses' age and they were newly graduated so they had less experience. This study agreed with Kunswa (2010) studying at Ain Shams university, Egypt, who entitled "Needs, Problem and Nursing Care of Neonates", and demonstrated that, the majority of studied nurses had experience ranged from 5-10 years with mean $5.5 \pm 3.01$ years.

Concerning previous training courses, the present study (table 1) showed that more than three quarters of nurses attended training courses. This result could be interpreted as intensive care unit are a critical place that needs good trainned nurses. This findings supported by Ahmed (2013), studying at Faculty of Nursing, Benha University, Egypt, in a study entitled "Quality of Nursing Care to Neonates Pre-Post Operation with Tracheotomy" who found that, more than half of the nurses attended training courses in NICU. Also these results in agreement with Aemri et al., (2016) in a study entitled "Effect of a Comprehensive Total Parenteral Nutrition Training Program on Knowledge and Practice of Nurses in NICU", Canadian Center of Science, stated that the training courses play an important role in enhancing and updating nurses' knowledge and performance. While it disagreed with Ebrahim (2014), Faculty 
of Nursing, Cairo University, Egypt, in a study about "assessment of nurses' knowledge regarding NEC" and found that the majority of nurses didn't have chance to attend training courses related to high risk neonates.

On the light of the study findings (figure1), it was evident that, the total knowledge level of nearly three quarters of nurses was average. This may be attributed to nurses' educational level. This study agreed with Hassan (2010) who found in his study made in London that the majority of nurses had an average level of knowledge regarding management of respiratory distress. Meanwhile, the study done by Ebrahim (2014) about "Assessment of Nurses' Knowledge Regarding NEC" revealed that the majority of nurses had unsatisfactory level of knowledge.

Regarding total performance of nurses (figure 2), the findings showed that exactly two thirds of nurses had unsatisfactory performance regarding care of neonates with necrotizing enterocolitis. This may be due to lack of inservice training and inadequate administration strategies. In the same line, Ibrahim (2013), Faculty of Nursing, Benha University, Egypt, about "Assessment of Nursing Care Given for Children with Intestinal Obstruction" found that more than two thirds of nurses had poor level of performance regarding nursing care for children with intestinal obstruction. Petty (2014), stated that neonatal nurse is functioning as first responders for high risk and emergency services and the one who is capable for providing safe, optimal care and decreasing medical errors for high risk neonates. Therefore, the neonatal nurse must submit to periodical exam to test their competence in caring for neonates.

Concerning relation between total nurses' knowledge and their age (table 3), there were statistical significant difference $(\mathbf{P} \leq \mathbf{0 . 0 5})$. This result may be due to updated knowledge of newly graduated young nurses. While study done by Ibrahim (2013) in a study about "Assessment of Nursing Care Given for Children with Intestinal Obstruction" found that there was no significant relation between nurses' knowledge and their age. Also, it disagreed with Ebrahim (2014) about "Assessment of Nurses' Knowledge Regarding NEC" who revealed that there was no statistical relation between their knowledge and ages.

According to relation between studied nurses' total knowledge scores and their qualification level (table 3), these findings reflected that, there was a statistical significant difference between studied nurses' total knowledge scores and their qualification level $(\mathbf{P} \leq \mathbf{0 . 0 5})$ This result could be interpreted as nurses with bachelor degree had more knowledge than nurses with diploma degree. These findings were consistent with the findings of the study done by Ebrahim (2014) about "Assessment of Nurses' Knowledge Regarding NEC" which showed that, there was statistical significant relation between nurses' knowledge and their qualifications as nurses, with high level of education, had appropriate knowledge. Loutfy (2014) also found that, there was high statistically significant relation between nurses' academic qualification and total nurses' knowledge scores.

Regarding relation between studied nurses' total knowledge scores and their years of experiences (table 3), the present study viewed that, there was a statistical significant difference between studied nurses' total knowledge and their years of experience. This may be due to keeping old age nurses away from updating knowledge. These findings contracted by Loutfy (2014) who stated 
that, there was no relation between years of experience of the studied nurses and total nurses' knowledge. In the same line, Abdel Halim (2013), Faculty of nursing, Ain Shams University, Egypt, in a study about "Care Given to High Risk Neonates", stated that there was no statistical relation between nurses' knowledge and their experience.

Regarding relation between studied nurses' total knowledge scores and their personal data (table 3), the results of the present study revealed that, there was a positive relation between studied nurses' total knowledge scores and their personal data. These findings were contradicted with Ameri et al., (2016) in a study entitled "Effect of Comprehensive Total Parenteral Nutrition Training Program on Knowledge and Practice of Nurses in NICU". This study found that, none of the demographic information affected the knowledge and practice scores of the nurses, either before or after the intervention.

In studying relation between total nurses' performance and their ages (table 4), it revealed that there was highly statistical significant relation. This reflects that updated knowledge of young nurses affected their performance. These findings agreed with Ahmed (2013) in a study entitled "Quality of Nursing Care to Neonates Pre-Post Operation with Tracheotomy", who found that there was statistical significant relation between total nurses' performance and their ages. Meanwhile, Leobardo (2012), Faculty of Nursing , Samar State University, Philippine who evaluated nursing pre and postoperative knowledge and performance and showed that there was no relation between nurses' performance and their ages.

Regarding relation between studied nurses' total performance scores and their qualification level (table 4), it was revealed that, there was statistical significant relation between nurses' total performance scores and their qualification level $(\mathbf{p}<\mathbf{0 . 0 5})$. These findings reflected that nurses with bachelor degree had better performance than diploma as high nurses used to follow checklist while training on procedures. It was supported by Loutfy (2014) who reported that, there was high statically significant relation between nurses' academic qualification and total nurses' practice score.

Concerning the relation total nurses' performance scores and their years of experience, the present study explained that, there was highly statistical significant difference $(\mathbf{p}=\mathbf{0 . 0 0 1})$. This result may reflect keeping of nurses who had more experience away from updating procedures guidelines. These findings were in consistent with Ahmed (2013) in a study entitled "Quality of Nursing Care to Neonates Pre-Post Operation with Tracheotomy", and found that, there was a positive relation between total nurses' performance scores and years of experience. This study contradicted with Loutfy (2014) who stated that there was no relation between years of nurses' experience of and their total performance scores.

It is evident from the results of the present study that, there was statistical significant correlation between total nurses knowledge scores and their total performance scores (table 5). The results indicated that poor knowledge scores of the nurses influenced nurses' performance. These findings supported by Daniel et al., (2013) in the study about " The Effectiveness of Structured Teaching Programme on Care of Neonates with Central Venous Access Device Among Staff Nurses in Selected Oncology Hospital of Bangalore ", and reported that, there was a positive statically 
significant correlation between total knowledge and performance with general characteristics of nurses.

\section{Conclusion:}

Based on the findings of the present study, it can be concluded that; more than two thirds of studied nurses had average total level of knowledge and two thirds of them had unsatisfactory performance. There was a positive correlation between total knowledge scores and total performance scores of the studied nurses.

\section{Recommendations:}

The following recommendations were suggested:

1.Developing a periodical training programs regarding care of neonates with necrotizing enterocolitis for nurses working in neonatal intensive care units to improve their performance.

2.Designing an illustrated booklet containing all tasks for nurses working in NICUs to be sure that all essential knowledge and performance related to necrotizing enterocolitis are in their hands and acts as standardized protocol for provision of standard of care.

\section{References}

Abdel-Halim, F.S., (2012): Nursing intervention for neonatal infection: An assessment study. Faculty of nursing.,Ain Shams University. P 45 , 81.

Afrazia, S., Richard, S., Neal, M., Sigger, R., and Hakam, d. (2011): New insights into the pathogenesis and treatment of NEC. Advances in Neonatal Care; 69(3): p183
Ahmed, R.A (2013): Quality of Nursing Care for Neonates with Tracheoesophageal Fistula (Pre\&Post-operative), Master

degree, Faculty of Nursing, Benha University, Egypt.pp 101-104.

Ambalavanan, N., (2011): Identification of extremely premature infants at high risk of rehospitalization. Pediatrics.;128(5): pp: 1216-1225

Ameri, Z., Vafaee, A., Sadeghi,T., Mirlashari, Z., Nejad, D., and Kalhor, F.(2016): Effect of A Comprehensive Total Parenteral Nutrition Training Program on Knowledge and Practice of Nurses in NICU, Canadian Center of Science and Education Journal, 8(10): p 135.

Ball, J.W., Bindler, R.C., and Cowen, K.J.(2012):Principle of pediatric nursing; Caring for children. ( $5^{\text {th }}$ ed.) U.S.A: Pearson Com. pp 778-780.

Bucher, H.U., (2013): The future of neonatology:possibilities and limitations. Praxis.102 (15): pp 919924.

Cassir, N., Simeoni. U., andScola, B., (2016): Gut microbiota and the pathogenesis of necrotizing enterocolitis in preterm neonates.FutureMicrobiol.;11(2): pp 273-292.

Clark, R., Gordon, P., Walker, M., Laughon, M. and Smith, P.(2011): Characteristics of children who die of necrotizing enterocolitis. Journal of perinatology. 32, pp: 199- 204

Cloherty, J.P., and John P. (2012):Care of the Extremely Low Birth Weight 
Infant". Manual of neonatal care $\left(7^{\text {th }}\right.$ ed.). Philadelphia: Wolters Kluwer Health/Lippincott Williams \& Wilkins. pp:146- 150.

Daniel, B., Nagaraju, B., Padmavathi ,G.V., Bolouri, A., Zothanmawia, C., and Sahar, S. (2013):The Effectiveness of Structured Teaching Programme on Care of Neonates Patient with Central Venous Access Device Among Staff Nurses in Selected Oncology Hospital of Bangalore, International Journal of Medicine and Medical Science Research, 1(1): p: 12.

Dominguez, K.,and Moss, R., (2012):Necrotizing enterocolitis. department of surgery;Available at: http://emedicine.medscape.com/article I.39 (2): p: 387.

Ebrahim, M.Y. (2014): Assessment of nurses' knowledge regarding necrotizing enterocolitis, Unpublished thesis, Master degree, Faculty of Nursing, Cairo University, Egypt.pp $75-81$.

Fayed, M.M., (2009) : Assessment of pre and post operative care given by nurses to children with intussusception, Master degree, Faculty of Nursing, Ain Shams University, Egypt.p: 68

Gordon, P.V., and Swanson, J.R., (2014): Necrotizing enterocolitis is one disease with many origins and potential means of prevention. Pathophysiology.Elsevier Ireland. $21\left(1^{\text {th }} \mathrm{ed}\right) . \mathrm{p}: 13$.

Hassan, A., (2010): Understanding mechanical ventilation; A practical handbook, $1^{\text {st }}$ ed London, Springer Heidelburg Publisher, Chapter 10, p: 305.
Ibrahim, H.S. (2013) : Assessment of nursing care given for children with intestinal obstruction" Master degree, Faculty of Nursing, Benha University, Egypt.pp:90 -93

Kim, L., (2010): Postoperative anesthesia care nursing, $2^{\text {nd }}$ ed., Mosby Company, p: 45-56.

Kunswa, A. (2010): Needs Problems and Nursing Care of Newborn Infant, Doctorate Thesis, Faculty of Nursing, Ain Shams university, Egypt. P 104.

Leopardo, J.(2012): Nurses' knowledge and practice of pre- postoperative care, Master thesis, Faculty of Nursing , Samar State University, Philippine,p:70,90

Loutfy A., (2014): Quality of Nursing Care Provided for Preterm Infants Suffering from Respiratory Distress Syndrome, Port Said scientific, Journal of Nursing 08-20, ISSN 2, p: 275 .

Patel, B.K., and Shah, J.S., (2012): Necrotizing enterocolitis in very low birth weight infant. Systemic Review, Journal of Pediatric Gastroenterology and Nutrition. . P 45.

Petty, J.,(2014): A global view of competency in Neonatal care. Journal of Neonatal Nursing. 20 (1): p: 10.

Zhou, P., Li, Y., Ma, L.Y., and Lin, H.C., (2015); The Role of Immunonutrients in the Prevention of Necrotizing Enterocolitis in Preterm Very Low Birth Weight Infants. Nutrients. 28;7 (9): pp: 7256-7270 